\title{
Voltage Profile Analysis in Power Transmission System based on STATCOM using Artificial Neural Network in MATLAB/SIMULINK
}

\author{
Amit Garg \\ Assistant Engineer, \\ Uttar Haryana Bijli Vitran Nigam, \\ Haryana, India.
}

\author{
Ravindra Pratap Singh \\ Director, \\ BDES Group of Institutions, \\ JB Knowledge Park, Faridabad, \\ Haryana, India.
}

\begin{abstract}
This paper deals with Voltage Stability Analysis in a Power Transmission System with and without STATCOM using Artificial Neural Network in MATLAB/ SIMULINK. It is shown that trained Neural Network developed has excellent capabilities of forecasting which can be very useful in research. Voltage control and reactive power compensation in a weak distribution networks for integration of wind power is also represented in this paper. For dynamic reactive power compensation, when,STATCOM (Static Synchronous Compensator) is a used at a point of interconnection of wind farm and the network; the system absorbs the generated wind power for maintaining its voltage level. Voltage level of the system changes on changing the values of resistive loads connected to transmission line and using these voltages on bus 1 and bus 2 on different values of loads a neural network is developed after training which can forecast voltage on bus 1 and bus 2 of the transmission line on any values of the resistive load connected to transmission line.
\end{abstract}

\section{Keywords}

Artificial Neural Network (ANN), Dynamic Performance, Induction generators, FACTs,Matlab/Simulink, Transient Stability, Voltage Profile Analysis.

\section{INTRODUCTION}

In this paper artificial transmission line of $50 \mathrm{KM}$ is simulated and tested. STATCOM is placed at the receiving end for balanced load condition. The receiving end voltage fluctuations were observed for different loads. STATCOM are used to improve voltage and reactive power conditions in AC systems. An additional task of STATCOM is to increase transmission capacity as result of power oscillation damping. In This paper the reactive power compensation capability of STATCOM for wind power integration into a weak distribution network is evaluated. The $9 \mathrm{MW}$ wind farm have conventional wind turbine systems consisting of squirrel-cage induction generators and variable pitch wind turbines[10]. Voltage profile of the system changes on variation of the values of loads connected to power transmission line and using these voltage values on bus 1 and bus 2 on different values of resistive loads a Artificial Neural Network is developed after training. Artificial Neural Network can now be used to forecast voltage values on bus 1 and bus 2 of the transmission line on any values of the resistive load connected to transmission line at any instant. An Artificial Neural Network is a system based on the operation of biological neural networks, in other words, is an emulation of biological neural system[22]. As its biological predecessor, an artificial neural network is an adaptive system. By adaptive, it means that each parameter is changed during its operation and it is deployed for solving the problem in matter. This is called the training phase[21]. Simulation results show that STATCOM devices significantly improve the performance of the wind farm and power network. This paper also presents Algorithm and Program in MATLAB for training of Artificial Neural Network for calculation of weights and biases and then using these weights and biases Program in MATLAB is presented for forecasting the voltage values on bus 1 and bus 2 of the power network on different values of Loads L1 and L2 at different time.

\section{SIMULATION OF TEST SYSTEM}

The network consists of a $132 \mathrm{kV}, 50 \mathrm{~Hz}$, grid supply point, feeding a $33 \mathrm{KV}$ distribution system through 132/33 KV, 62.5 MVA step down transformer. There are two resistive loads in the system L1 AND L2.The $33 \mathrm{kV}, 50 \mathrm{kM}$ long line is modeled as line. A $9 \mathrm{MW}$ wind farm is to be connected to the $33 \mathrm{kV}$ distribution network. The total MVA loading on the system is 50 MVA; considering the T \& D losses in the system it is over loaded and representing weak distribution network. Dynamic compensation of reactive power is provided by a STATCOM located at the point of wind farm connection.

The simulation is run in three different modes, as follows -

i. Without wind farm and STATCOM,

ii. With wind farm and without STATCOM,

iii. With wind farm and STATCOM

\section{SIMULATION}

\subsection{Without Wind Farm and STATCOM}

In this mode the wind farm and STATCOM were skipped while running the simulation. Only the distribution system and two loads were kept in the model. The purpose of running the simulation in this mode is to ascertain that, the test system is a weak system. Only voltages at $33 \mathrm{kV}$ Bus -1 and Bus -2 are measured. 


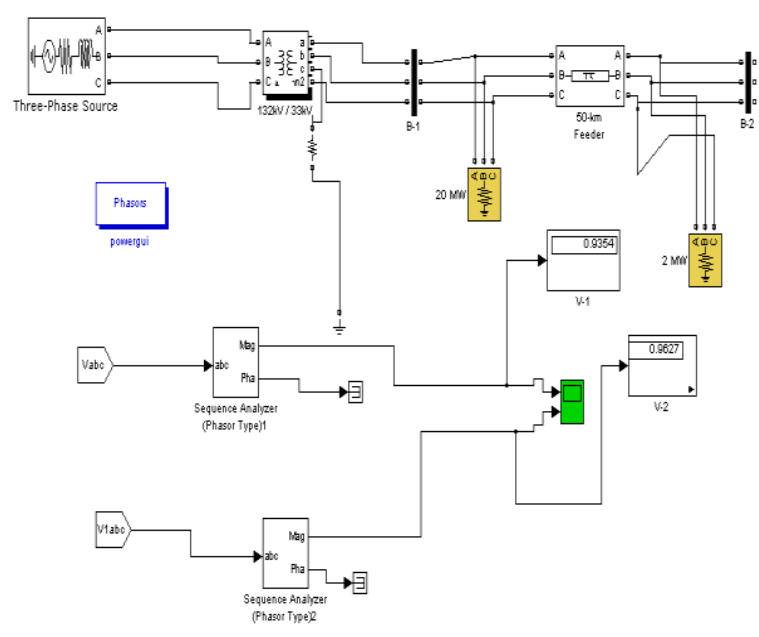

Fig 1: Simulink Model of the test system without wind farm andSTATCOM

\subsection{With Wind Farm and without \\ STATCOM}

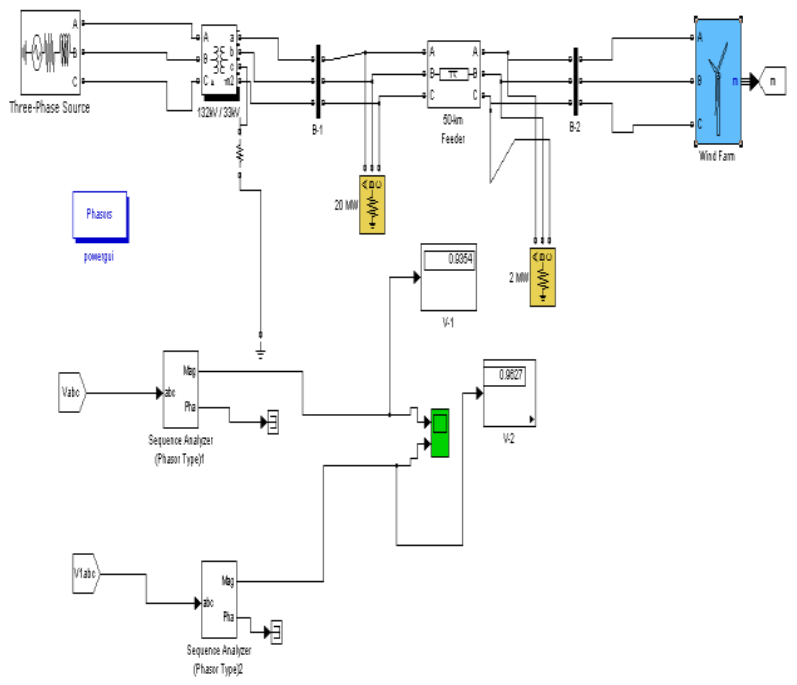

Fig 2: Simulink Model of the test system with wind farm and without STATCOM

In this mode of simulation the wind farm is connected to the weak distribution network in above mode. The purpose of running simulation in this mode is to try integration of $9 \mathrm{MW}$ wind power in weak distribution network, without dynamic compensation of reactive power i.e. without using the STATCOM. Before tripping the wind turbine generators have drawn reactive power from the network.

\subsection{With Wind Farm and with STATCOM}

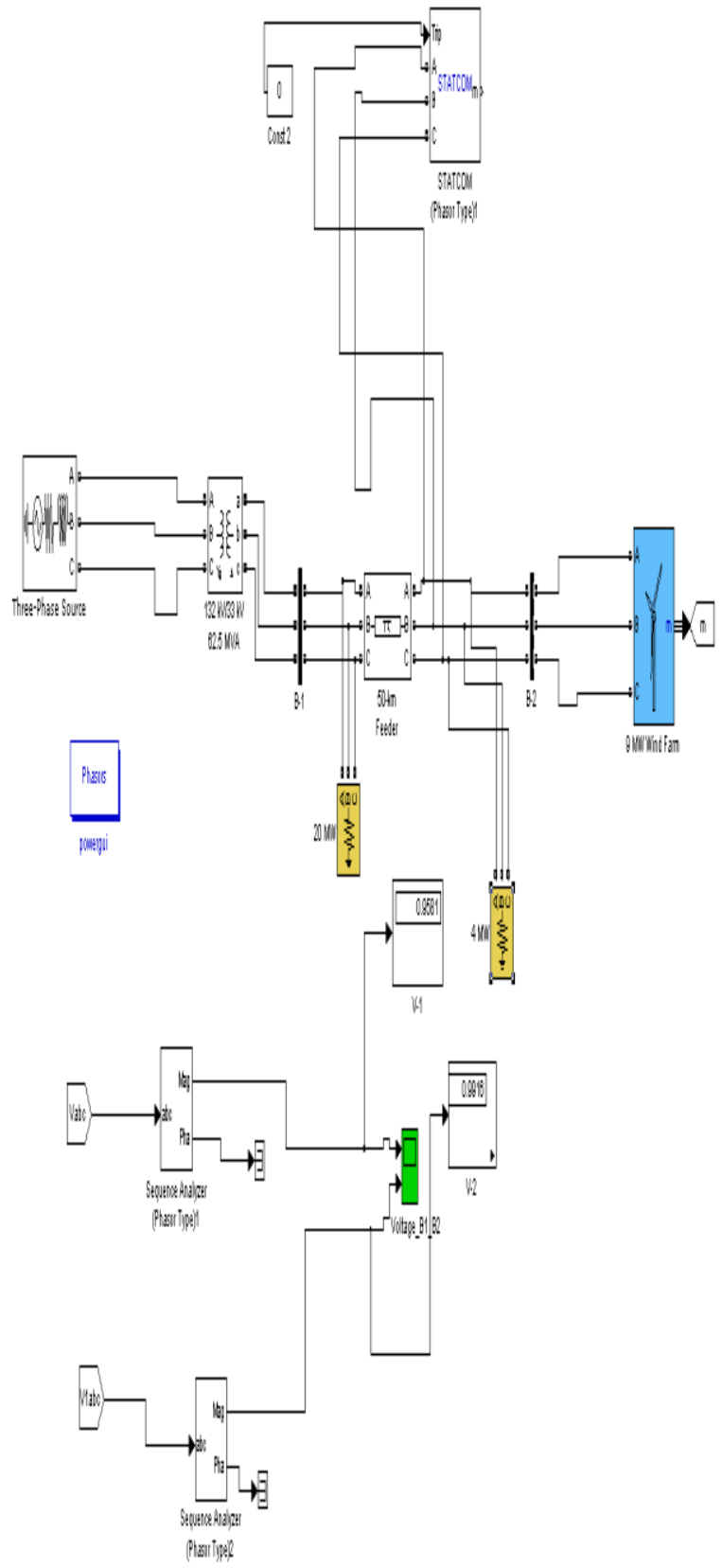

Fig 3: Simulink Model of the test system with wind farm and STATCOM

In this mode of simulation the wind farm with dynamic compensation by STATCOM is connected to the weak distribution network in above mode. The purpose of running simulation in this mode is to integrate $9 \mathrm{MW}$ wind power in weak distribution network, with dynamic compensation of reactive power using the STATCOM.

\section{ARTIFICIAL NEURAL NETWORK}

Artificial neural networks born after McCulloc and Pitts introduced a set of simplified neurons in 1943. These neurons were represented as models of biological networks into conceptual components for circuits that could perform computational tasks. The basic model of the artificial neuron is founded upon the functionality of the biological neuron. By definition, "Neurons are basic signaling units of the nervous 
system of a living being in which each neuron is a discrete cell whose several processes are from its cell body. One can differentiate between two basic types of networks, networks with feedback and those without it. In networks with feedback, the output values can be traced back to the input values. However there are networks wherein for every input vector laid on the network, an output vector is calculated and this can be read from the output neurons[23]. There is no feedback. Hence only, a forward flow of information is present. Network having this structure are called as feed forward networks. There are various nets that come under the feed forward type of nets. A multilayer feed forward back propagation network with one layer of z-hidden units. The $\mathrm{Y}$ output unit has $\mathrm{W}_{\mathrm{ok}}$ bias and $\mathrm{Z}$ hidden unit has $\mathrm{V}_{\mathrm{ok}}$ as bias. It is found that both the output units and the hidden units have bias. The bias acts like weights on connection from units whose output is always 1 . This network has one input layer, one hidden layer and one output layer. There can be any number of hidden layers[22]. The input layer is connected to the hidden layer and the hidden layer is connected to the output layer by means of interconnection weights. The bias is provided for both the hidden and the output layer, to act upon the net input to be calculated [20].

\section{TRAINING ALGORITHM}

The training algorithm of back propagation involves four stages[18], viz.

\section{Initialization of Weights \\ 2. Feed Forward \\ 3. Back Propagation of errors \\ 4. Updation of the weights and the biases.}

During first stage which is the initialization of weights, some small random values are assigned. During feed forward stage each input unit $\left(\mathrm{X}_{\mathrm{i}}\right)$ receives an input signal and transmits this signal to each of the hidden units $\mathrm{Z1}$......... $\mathrm{Zp}$. Each hidden unit then calculates the activation function and sends its signal $\mathrm{Zj}$ to each output unit. The output unit calculates the activation function to form the response of the net for the given input pattern. During back propagation of errors, each output unit compares its computed activation $y_{k}$ with its target value $t_{k}$ to determine the associated error for that pattern with that unit. Based on the error, the factor $\delta_{\mathrm{k}}$ is computed and is used to distribute the error at output unit $y_{k}$ back to all units in the previous layer. Similarly factor $\delta_{\mathrm{j}}$ is computed for each hidden unit $\mathrm{z}_{\mathrm{j}}$.During final stage, the weight and biases are updated using the $\delta$ factor and the activation

$\mathrm{x}$ : input training vector

$\mathrm{x}:\left(\mathrm{x}_{1}, \ldots \ldots \ldots . \mathrm{x}_{\mathrm{i}}, \ldots, \mathrm{x}_{\mathrm{n}}\right)$

$\mathrm{t}$ : Output target vector

$\mathrm{t}:\left(\mathrm{t}_{1}, \ldots \ldots \ldots . . \mathrm{t}_{\mathrm{i}}, \ldots ., \mathrm{t}_{\mathrm{n}}\right)$

$\delta_{\mathrm{k}}=$ error at output unit $\mathrm{y}_{\mathrm{k}}$

$\delta_{\mathrm{j}}=$ error at hidden unit $\mathrm{zj}$

$\dot{\alpha}=$ learning rate

$\mathrm{V}_{\mathrm{oj}}=$ bias on hidden unit $\mathrm{j}$

$\mathrm{zj}=$ hidden unit $\mathrm{j}$ $\mathrm{w}_{\mathrm{ok}}=$ bias on output unit $\mathrm{k}$

$\mathrm{y}_{\mathrm{k}}=$ output unit $\mathrm{k}$.

The training algorithm used in the back propagation network is as follows. The algorithm is given with the various phases:

\subsection{Initialization of Weights}

Step 1: Initialize weight to small random values.

Step 2: While stopping condition is false, do Steps 3-10.

Step 3: For each training pair do steps 4-9.

\subsection{Feed Forward}

Step 4: Each input unit receives the input signal $\mathrm{x}_{\mathrm{i}}$ and transmits this signals to all units in the layer above i.e hidden units.

Step 5: Each hidden unit $\left(z_{j}, j=1, \ldots \ldots, p\right)$ sums its weighted input signals.

$\mathrm{z}_{-\mathrm{inj}}=\mathrm{v}_{\mathrm{oj}}+\Sigma \mathrm{x}_{\mathrm{i}} \mathrm{v}_{\mathrm{ij}}$

applying activation function

$\mathrm{Z}_{\mathrm{j}}=\mathrm{f}\left(\mathrm{z}_{\mathrm{inj}}\right)$

and sends this signal to all units in the layer above i.e. output units.

Step 6: Each output unit $\left(\mathrm{y}_{\mathrm{k}}\right)$ sums its weighted input signals.

$\mathrm{y}_{\text {-ink }}=\mathrm{w}_{\mathrm{ok}}+\Sigma \mathrm{zj} \mathrm{w}_{\mathrm{jk}}$

and applies its activation function to calculate the output signals.

$Y_{k}=f\left(y-{ }^{-i n k}\right)$

\subsection{Back Propagation of Errors}

Step 7: Each output unit receives a target pattern corresponding to an input pattern, error information term is calculated as

$\delta_{\mathrm{k}}=\left(\mathrm{t}_{\mathrm{k}}-\mathrm{y}_{\mathrm{k}}\right) \mathrm{f}(\mathrm{y}$-ink $)$

Step 8: Each hidden unit (zj) sums its delta inputs from units in the layer above

$$
\delta_{\text {-inj }}=\Sigma \delta j w_{\mathrm{jk}}
$$

The error information term is calculated as

$$
\delta_{\mathrm{j}}=\delta_{\text {-inj }} \mathrm{f}\left(\mathrm{Z}_{\text {-inj }}\right)
$$

\subsection{Updation of Weight and Biases}

Step 9: Each output unit (yk) updates its bias and weights $(j=0, \ldots . ., p)$

The weight correction term is given by 
$\Delta \mathrm{W}_{\mathrm{jk}}=\alpha \delta_{\mathrm{k}} \mathrm{zj}$

and the bias correction term is given by

$$
\Delta \mathrm{W}_{\mathrm{ok}}=\alpha \delta_{\mathrm{k}}
$$

Therefore $\mathrm{W}_{\mathrm{jk}}($ new $)=\mathrm{W}_{\mathrm{jk}}($ old $)+\Delta \mathrm{W}_{\mathrm{jk}}, \quad \mathrm{W}_{\mathrm{ok}}($ new $)=\mathrm{W}_{\mathrm{ok}}$ (old) $+\Delta \mathrm{W}_{\mathrm{ok}}$

Each hidden unit $(\mathrm{zj}, \mathrm{j}=1, \ldots \ldots . \mathrm{p})$ updates its bias and weights $(\mathrm{i}=0, \ldots \ldots \mathrm{n})$

The weight correction term

$\Delta \mathrm{V}_{\mathrm{ij}}=\alpha \delta_{\mathrm{j}} \mathrm{xi}$

The bias correction term

$\Delta \mathrm{V}_{\mathrm{oj}}=\alpha \dot{\alpha} \delta_{\mathrm{j}}$

Therefore, $\mathrm{V}_{\mathrm{ij}}$ (new) $=\mathrm{V}_{\mathrm{ij}}($ old $)+\Delta \mathrm{V}_{\mathrm{ij}}, \quad \mathrm{V}_{\mathrm{oj}}($ new $)=\mathrm{V}_{\mathrm{oj}}($ old $)+$ $\Delta \mathrm{V}_{\mathrm{oj}}$

Step 10: Test the stopping condition.

The stopping condition may be the minimization of the errors, number of epochs etc.

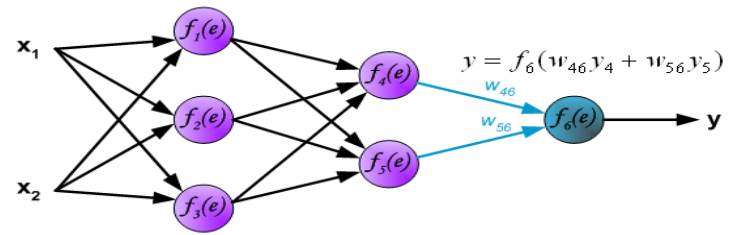

Fig 4: Feed Forward Networks

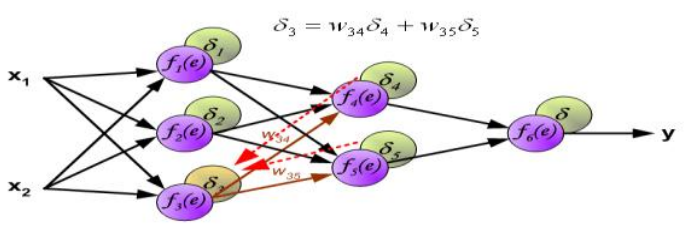

Fig 5: Back Propagation of Errors

\section{MATLAB PROGRAMS FOR ANN 6.1 Program for Training of Neural Network}

From SIMULINK Model of IG with STATCOM shown in Fig. 3 value of voltage at bus -1 is taken different time(s) from display block of the simulation at different values of Load (L1(MW), L2(MW)) and Time(s). These values of L1, L2 , Time(s) are also mentioned in Table 1. Now from these different values of L1, L2 and Time(s) a neural network is trained through $\mathrm{a} \mathrm{x}$ : which is a input training vector as mentioned in Training Algorithm explained in section 5. Input traing vector in this case is L1 ,L2 and Time(s). Output target vector $t$ is Voltage V1(p.u) at bus -1 in this case. Weight $\mathrm{W}$ and $\mathrm{v}$ are initialized to small random values. $\mathrm{W}_{0}$ and $\mathrm{V}_{0}$ are bias. Iterations done in this program are 990000000.

clc

clear;

$\mathrm{W}=[-3.2184 ;-12.5463 ; 0.6328]$;
$\mathrm{Wo}=[9.5708]$

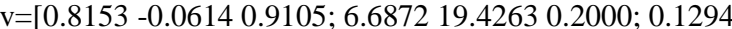

$0.03240 .2064]$;

$\mathrm{vo}=\left[\begin{array}{lll}0.4346 & 0.8483 & -0.4499\end{array}\right]$

$\mathrm{x}=\left[\begin{array}{llllll}.020 & .020 & .040 & 040 & 040 & 040\end{array}\right]$ .030 .035 .035 .002 .002 .004 .004 ;

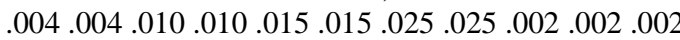
.002.002.002.010.010.020.020;

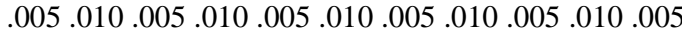
$.010 .005 .010 .005 .010 .005 .010]$;

$\mathrm{t}=\left[\begin{array}{l}.9458 .9272 .8163 .7078 .9836 .9403 .8986 .7718 .9614 \\ \hline\end{array}\right.$ .9593.9088.8813.8867.85.9952.9842.9253.8014]; epoch $=1$;

alpha=.3;

while $($ epoch $<990000000)$

for $\mathrm{I}=1: 18$

for $\mathrm{i}=1: 3$

$\operatorname{zin} 1=0$;

for $j=1: 3$

zin $1=\mathrm{zin} 1+\mathrm{x}(\mathrm{j}, \mathrm{I}) * \mathrm{v}(\mathrm{j}, \mathrm{i})$;

end

$\operatorname{zin}(\mathrm{i})=\operatorname{zin} 1+\operatorname{vo}(\mathrm{i}) * 1$;

$z(i)=1 /(1+\exp (-\operatorname{zin}(i)))$

end

yin $1=0$;

for $i=1: 3$

yin $1=y i n 1+z(i) * W(i, 1)$;

end

yin $1=$ yin $1+$ Wo

$\mathrm{y}(\mathrm{I})=1 /(1+\exp (-\mathrm{yin} 1))$;

delta1 $=(\mathrm{t}(\mathrm{I})-\mathrm{y}(\mathrm{I})) *(\mathrm{y}(\mathrm{I})) *(1-\mathrm{y}(\mathrm{I}))$;

for $\mathrm{i}=1: 3$

$\operatorname{delin}(\mathrm{i})=\operatorname{delta} 1 * \mathrm{~W}(\mathrm{i}, 1)$;

$\operatorname{del}(\mathrm{i})=\operatorname{delin}(\mathrm{i}) * \mathrm{z}(\mathrm{i}) *(1-\mathrm{z}(\mathrm{i}))$; end

for $i=1: 3$

for $j=1: 3$

$\operatorname{delv}(\mathrm{i}, \mathrm{j})=\operatorname{alpha} * \mathrm{x}(\mathrm{i}, \mathrm{I}) * \operatorname{del}(\mathrm{j})$;

$v(i, j)=v(i, j)+\operatorname{delv}(i, j)$;

end

delvo(i)=alpha* $1 * \operatorname{del}(\mathrm{i})$;

vo(i)=vo(i)+delvo $(i)$;

end

for $\mathrm{i}=1: 3$

$\operatorname{delW}(\mathrm{i})=\operatorname{alpha} * \mathrm{z}(\mathrm{i}) * \operatorname{delta} 1 ;$

$\mathrm{W}(\mathrm{i}, 1)=\mathrm{W}(\mathrm{i}, 1)+\operatorname{del} \mathrm{W}(\mathrm{i})$

end

delwo=alpha $* 1 *$ delta 1 ;

Wo=Wo+delwo;

end

epoch=epoch +1 ;

end

$\mathrm{y}$

epoch

$\mathrm{W}$

Wo

vo

Output of the Training Program are Weights (W and V) and Bias $\left(\mathrm{W}_{0}\right.$ and $\left.\mathrm{V}_{0}\right)$. Now using these values of Weights and Bias in Neural Network at any values of L1,L2 and Time (s) and values of voltage V1(p.u) can be easily forecasted through a program in MATLAB explained in section 6.2. 


\subsection{Program for Forecasting Voltage}

Now using this MATLAB Program at values of L1,L2 andTime (s) values of voltage V1(p.u) is forecasted. In Table 6.7 voltage $\mathrm{V} 1$ (p.u) is calculated through both with SIMULINK and Neural Network and Percentage error is calculated.

clc;

clear;

$\mathrm{W}=[-30.0447$;

-16.8708 ;

96.2814];

$\mathrm{Wo}=[5.8332] ;$

$\mathrm{v}=\left[\begin{array}{lll}25.0426 & 47.8485 & 72.5170 \text {; }\end{array}\right.$

$68.8580 \quad 71.6322 \quad 150.2044$

$115.7327 \quad-42.5198 \quad 13.4404]$;

$\mathrm{vo}=\left[\begin{array}{lll}-4.6538 & -2.9692 & -7.5148\end{array}\right]$;

$\mathrm{x}=[.010 ; .008 ; .010]$;

$\mathrm{I}=1$

for $\mathrm{i}=1: 3$

zin $1=0$;

for $\mathrm{j}=1: 3$

end

$$
\operatorname{zin} 1=\operatorname{zin} 1+x(\mathrm{j}, \mathrm{I}) * \mathrm{v}(\mathrm{j}, \mathrm{i}) \text {; }
$$

$\operatorname{zin}(\mathrm{i})=\operatorname{zin} 1+\operatorname{vo}(\mathrm{i}) * 1$

$z(i)=1 /(1+\exp (-\operatorname{zin}(i)))$;

end

yin $1=0$;

for $\mathrm{i}=1: 3$

end

yin $1=y$ in $1+z(i) * W(i, 1)$;

yin $1=$ yin $1+$ Wo

$y(I)=1 /(1+\exp (-\operatorname{yin} 1))$;

$$
\mathrm{y}
$$

\section{SIMULATION RESULTS}

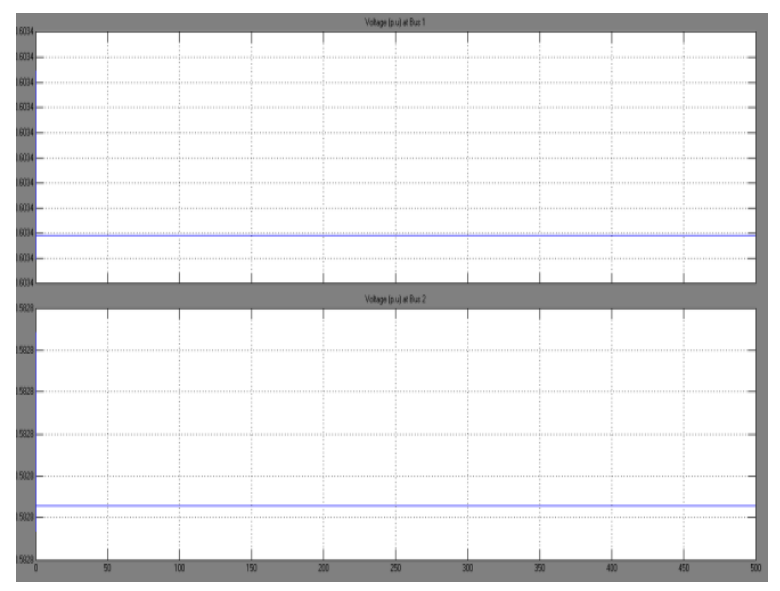

Fig 6: Voltage profile at bus 1 and 2 without Wind Farm and STATCOM.

From this Fig. it seen that the voltage at $33 \mathrm{kV}$ Bus -1 is $0.6034 \mathrm{pu}$. Where as the voltage at $33 \mathrm{kV}$ Bus -2 is 0.5828 pu.

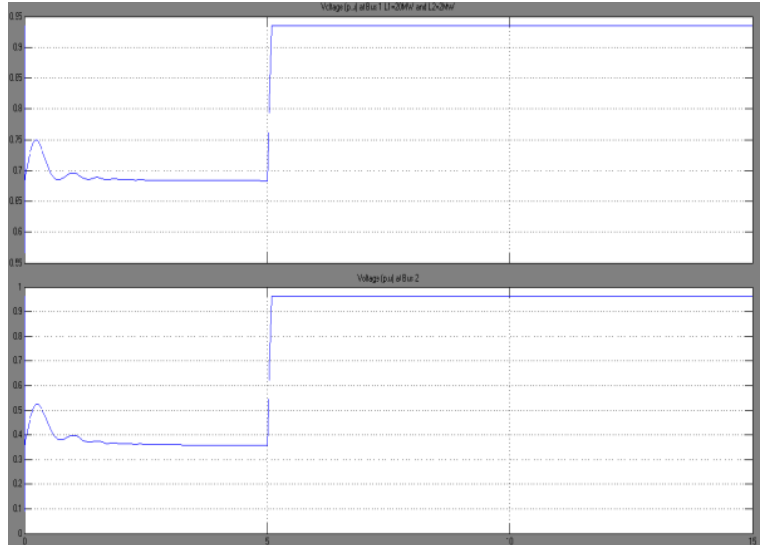

Fig 7: Voltage profile at bus 1 and 2 with Wind Farm and without STATCOM for $L 1=20 \mathrm{MW}$ and $\mathrm{L2}=\mathbf{2} \mathrm{MW}$.

Before tripping the wind turbine generators have drawn reactive power from the network. As a result the voltage at 33 $\mathrm{kV}$ Bus -2 as well as Bus -1 is decreasing, thereby causing under voltage tripping of wind turbine generators. Fig. shows the voltages at $33 \mathrm{kV}$ Bus -1 and $33 \mathrm{kV}$ Bus -2 .

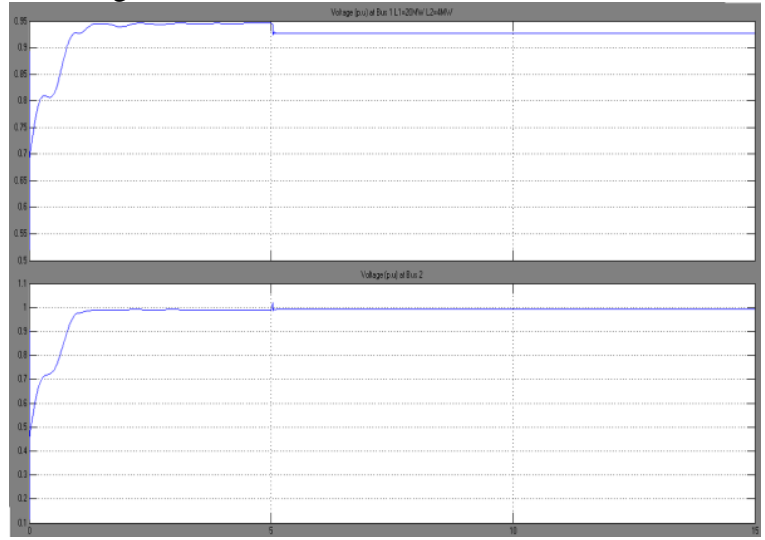

Fig. 8: Voltage profile at bus 1 and 2 with Wind Farm and STATCOM when $L 1=20 \mathrm{MW}$ and $L 2=4 \mathrm{MW}$.

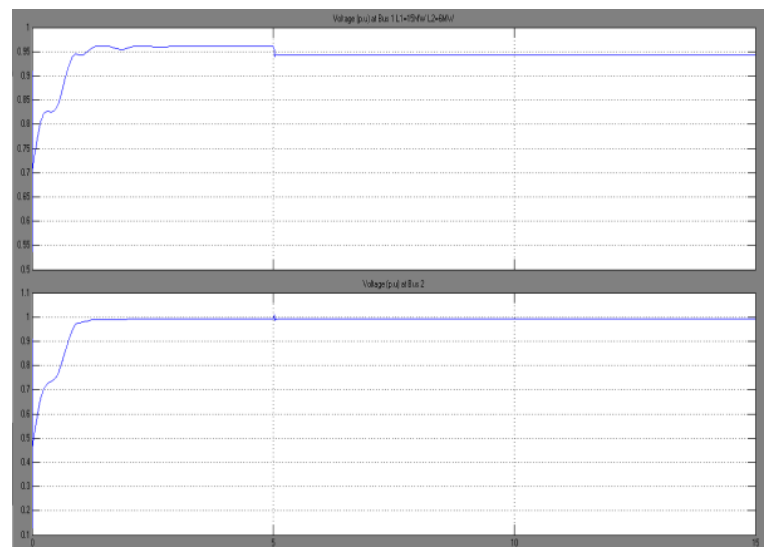

Fig.9: Voltage profile at bus 1 and 2 with Wind Farm and STATCOM when $L 1=40 \mathrm{MW}$ and $L 2=10 \mathrm{MW}$ 


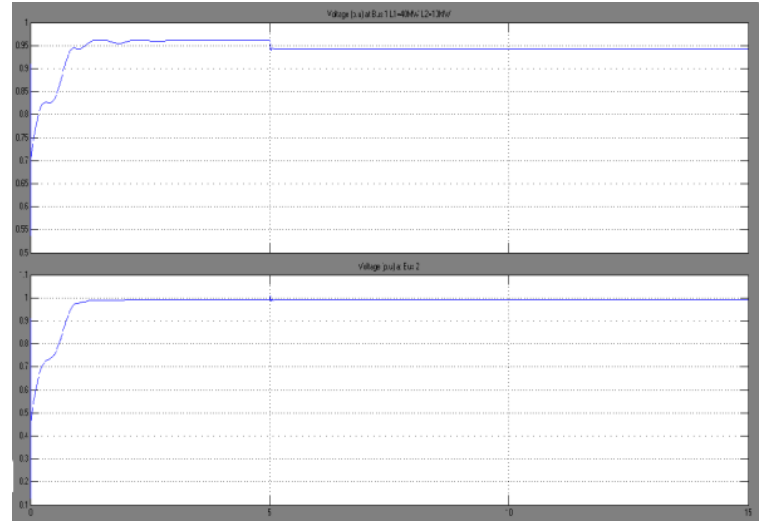

Fig.10: Voltage profile at bus 1 and 2 with Wind Farm and STATCOM $L 1=15 M W$ and $L 2=6 M W$

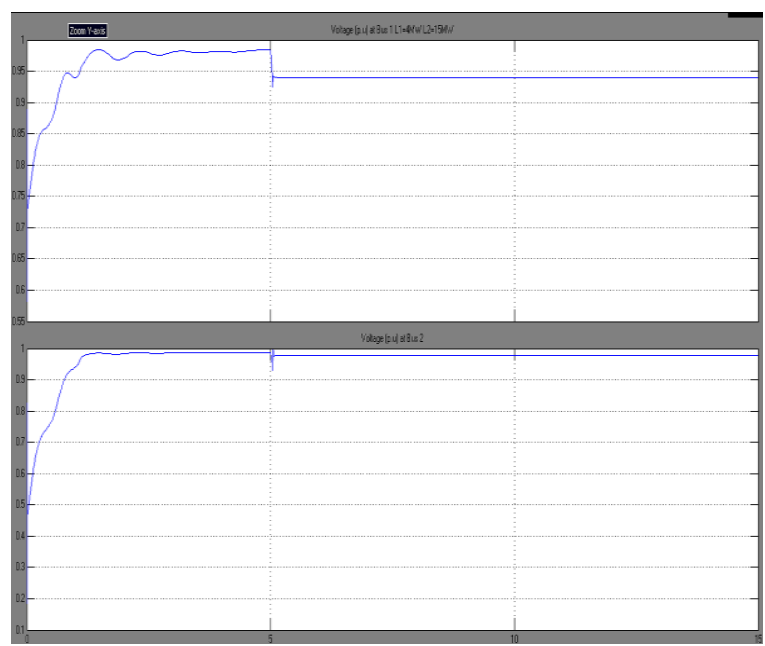

Fig. 11: Voltage profile at bus 1 and 2 with Wind Farm and STATCOM L1=4MW and $L 2=15 \mathrm{MW}$

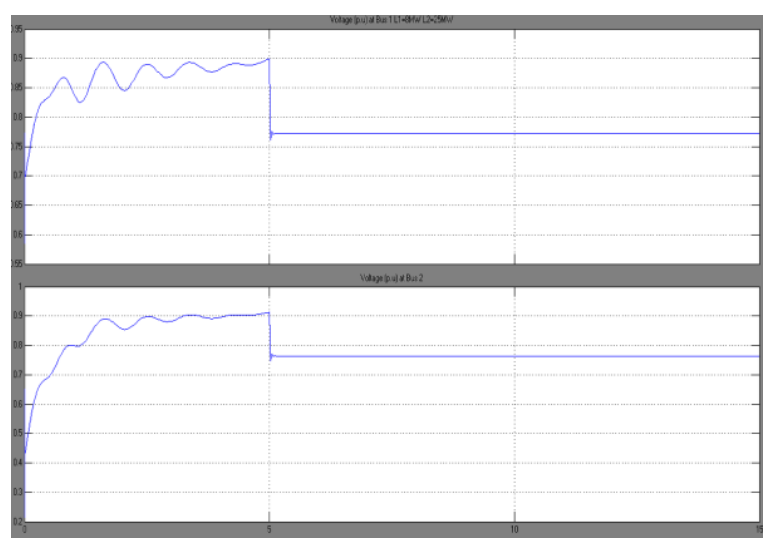

Fig.12: Voltage profile at bus 1 and 2 with Wind Farm and STATCOM L1=8 MW and $L 2=25 \mathrm{MW}$

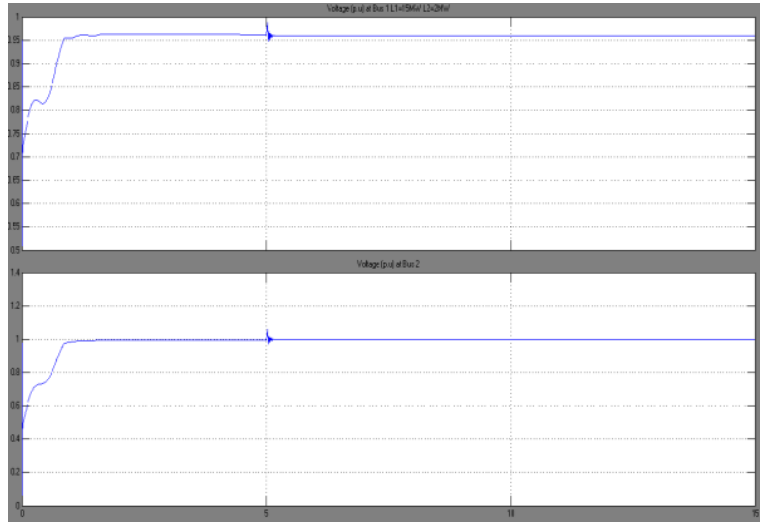

Fig.13: Voltage profile at bus 1 and 2 with Wind Farm and STATCOM L1=15 MW and $L 2=2 \mathrm{MW}$

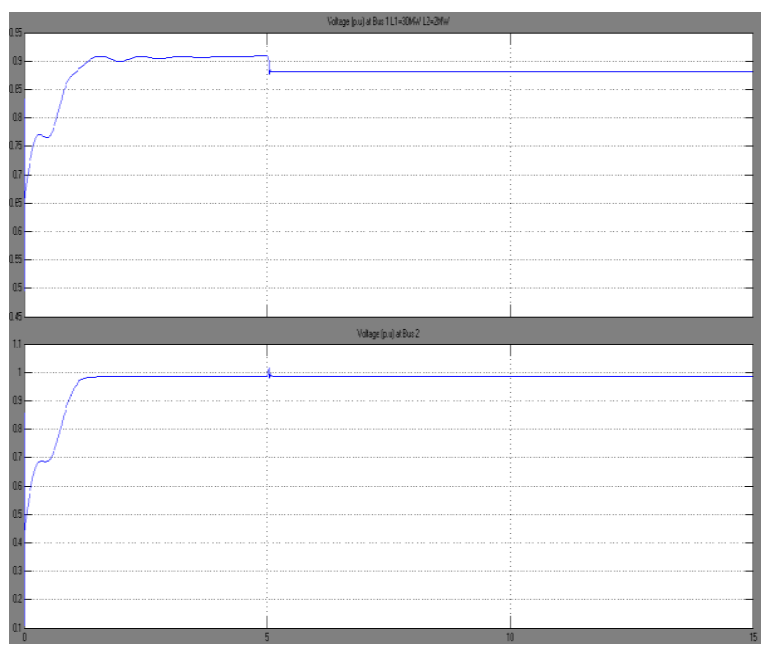

Fig.14: Voltage profile at bus 1 and 2 with Wind Farm and STATCOM L1=30MW and $L 2=2 M W$.

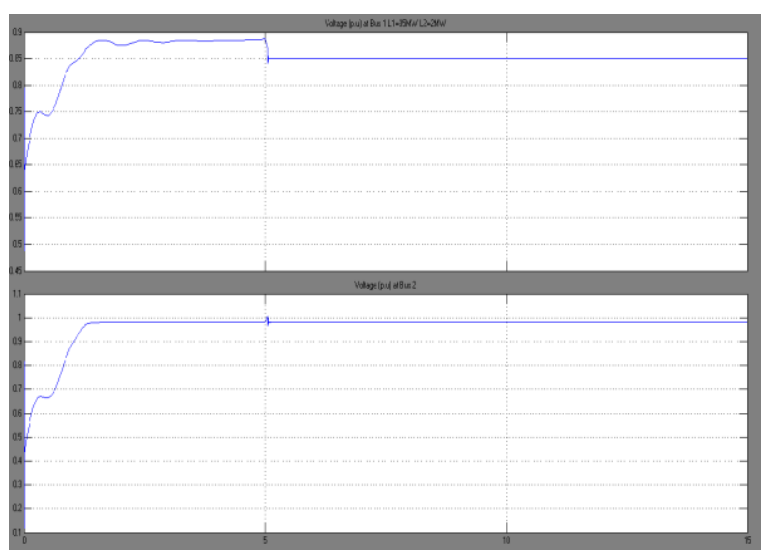

Fig.15: Voltage profile at bus 1 and 2 with Wind Farm and STATCOM $L 1=35 M W$ and $L 2=2 M W$. 


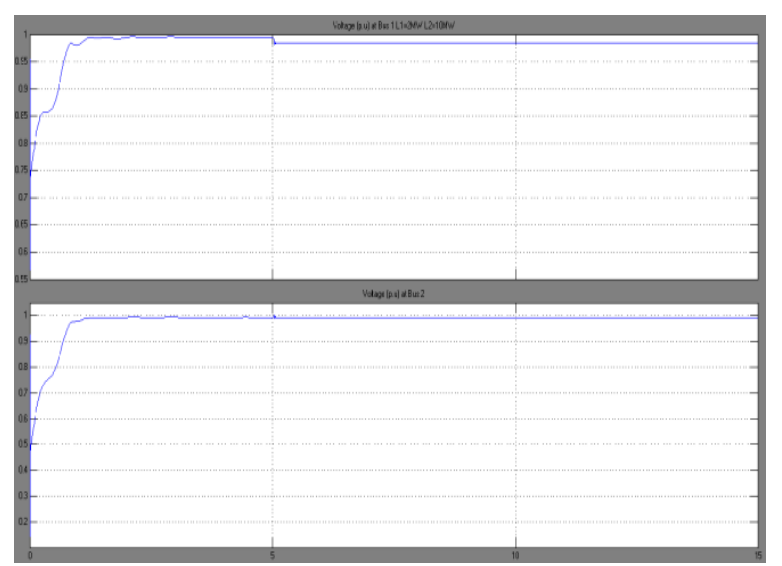

Fig.16: Voltage profile at bus 1 and 2 with Wind Farm and STATCOM $L 1=2 M W$ and $L 2=10 \mathrm{MW}$.

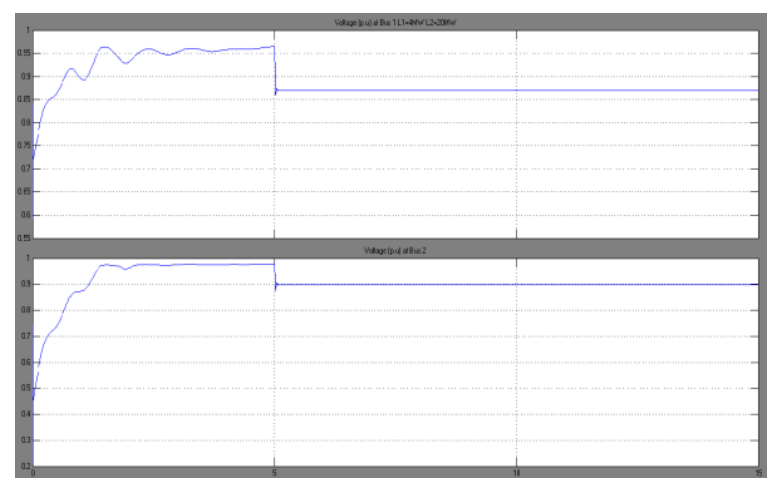

Fig.17: Voltage profile at bus 1 and 2 with Wind Farm and STATCOM L1=4 MW and $L 2=20 \mathrm{MW}$.

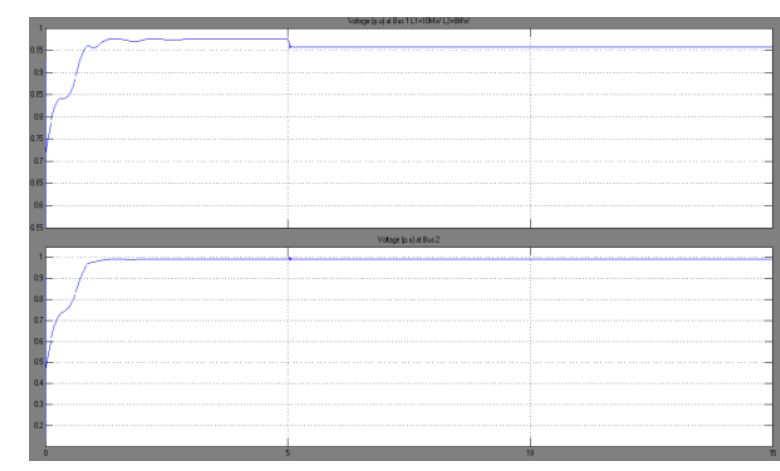

Fig.18: Voltage profile at bus 1 and 2 with Wind Farm and STATCOM $L 1=10 \mathrm{MW}$ and $L 2=8 \mathrm{MW}$.

Output of Program in MATLAB for training of Neural Network is as under:

$\mathrm{y}=\left[\begin{array}{llllll}0.9558 & 0.9359 & 0.8182 & 0.7089 & 0.9725 & 0.9428\end{array}\right.$

$\begin{array}{llllll}0.9083 & 0.7672 & 0.9763 & 0.9671 & 0.9222 & 0.8920\end{array}$

$\begin{array}{llllll}0.8800 & 0.8365 & 0.9746 & 0.9595 & 0.9095 & 0.8109]\end{array}$

epoch $=99000000$

$\mathrm{W}=[-30.0447$

$-16.8708$

96.2814]

Wo $=5.8332$

$\mathrm{v}=\left[\begin{array}{lll}25.0426 & 47.8485 & 72.5170\end{array}\right.$

$\begin{array}{lll}68.8580 & 71.6322 & 150.2044\end{array}$

$115.7327 \quad-42.5198 \quad 13.4404]$

vo $=\left[\begin{array}{lll}-4.6538 & -2.9692 & -7.5148\end{array}\right]$

Table 1. Values of Voltage on bus 1 and bus2 obtained through Matlab/Simulink and through Neural Network

\begin{tabular}{|c|c|c|c|c|c|c|c|c|}
\hline \multirow{2}{*}{$\begin{array}{l}\text { Sr. } \\
\text { No. } \\
1\end{array}$} & \multirow{2}{*}{$\begin{array}{l}\text { Value of Load L1 } \\
\text { and L2 (MW) } \\
L 1=20, L 2=4\end{array}$} & \multirow{2}{*}{$\begin{array}{l}\begin{array}{l}\text { Time } \\
(s)\end{array} \\
5\end{array}$} & \multicolumn{2}{|c|}{$\begin{array}{l}\text { Voltage at Bus land } \\
\text { Bus } 2 \text { obtained } \\
\text { through SIMULINK } \\
\text { (p.u) }\end{array}$} & \multicolumn{2}{|c|}{$\begin{array}{l}\text { Voltage at Bus land } \\
\text { Bus } 2 \text { obtained } \\
\text { through ANN (p.u) }\end{array}$} & \multicolumn{2}{|c|}{ Error (\%) } \\
\hline & & & .9458 & .9904 & .9558 & .9507 & -1.05 & 4 \\
\hline 2 & $L 1=20, L 2=4$ & 10 & .9272 & .9916 & .9360 & .9420 & -.9 & 5 \\
\hline 3 & $L 1=20, L 2=4$ & 15 & .9272 & .9916 & .9360 & .9420 & -.94 & 5 \\
\hline 4 & $L 1=15, L 2=6$ & 5 & .9616 & .9914 & .9611 & .9554 & .05 & 3.63 \\
\hline 5 & $L 1=15, L 2=6$ & 10 & .9432 & .9918 & .9415 & .9475 & .180 & 4.46 \\
\hline 6 & $L 1=15, L 2=6$ & 15 & .9432 & .9918 & .9415 & .9475 & .18 & 4.46 \\
\hline 7 & $L 1=40, L 2=10$ & 5 & .8163 & .9512 & .8188 & .5162 & -.30 & 4.57 \\
\hline 8 & $L 1=40, L 2=10$ & 10 & .7078 & .8435 & .7104 & .4692 & -.36 & 44 \\
\hline 9 & $L 1=40, L 2=10$ & 15 & .7078 & .8435 & .7104 & .4692 & -.36 & 44 \\
\hline 10 & $L 1=4, L 2=15$ & 5 & .9836 & .9866 & .9464 & .9292 & 3.78 & 5.8 \\
\hline 11 & $L 1=4, L 2=15$ & 10 & .9403 & .9782 & .9014 & .9169 & 4.13 & 4 \\
\hline 12 & $L 1=4, L 2=15$ & 15 & .9403 & .9782 & .9014 & .9169 & 4.13 & 4 \\
\hline 13 & $L 1=8, L 2=25$ & 5 & .8986 & .9126 & .9088 & .6214 & -1.13 & 31.9 \\
\hline 14 & $L 1=8, L 2=25$ & 10 & .7718 & .7641 & .7703 & .5774 & .194 & 24.4 \\
\hline
\end{tabular}




\begin{tabular}{|c|c|c|c|c|c|c|c|c|}
\hline 15 & $L 1=8, L 2=25$ & 15 & .7718 & .7641 & .7703 & .5774 & .194 & 24.4 \\
\hline 16 & $L 1=15, L 2=2$ & 5 & .9614 & .9936 & .9763 & .9752 & -1.54 & 18.5 \\
\hline 17 & $L 1=15, L 2=2$ & 10 & .9593 & .9982 & .9672 & .9708 & -.823 & 27.44 \\
\hline 18 & $L 1=15, L 2=2$ & 15 & .9513 & .9982 & .9672 & .9708 & -.82 & 27.44 \\
\hline 19 & $L 1=30, L 2=2$ & 5 & .9088 & .9861 & .9225 & .9182 & -1.50 & 6.88 \\
\hline 20 & $L 1=30, L 2=2$ & 10 & .8813 & .9869 & .8926 & .9039 & -1.28 & 8.4 \\
\hline 21 & $L 1=30, L 2=2$ & 15 & .8813 & .9869 & .8926 & .9039 & -1.28 & 8.4 \\
\hline 22 & $L 1=35, L 2=2$ & 5 & .8867 & .9830 & .8811 & .8775 & .631 & 10.7 \\
\hline 23 & $L 1=35, L 2=2$ & 10 & .85 & .9823 & .8377 & .8568 & 1.44 & 12.7 \\
\hline 24 & $L 1=35, L 2=2$ & 15 & .85 & .9823 & .8377 & .8568 & 1.44 & 12.7 \\
\hline 25 & $L 1=2, L 2=10$ & 5 & .9952 & .9932 & .9747 & .9710 & 2.05 & 2.2 \\
\hline 26 & $L 1=2, L 2=10$ & 10 & .9842 & .9929 & .9595 & .9659 & 2.50 & 2.71 \\
\hline 27 & $L 1=2, L 2=10$ & 15 & .9842 & .9929 & .9595 & .9659 & 2.50 & 2.71 \\
\hline 28 & $L 1=4, L 2=20$ & 5 & .9253 & .9347 & .9094 & .8519 & 1.71 & 8.8 \\
\hline 29 & $L 1=4, L 2=20$ & 10 & .8014 & .7894 & .8097 & .8281 & -1.03 & -4.9 \\
\hline 30 & $L 1=4, L 2=20$ & 15 & .8014 & .7894 & .8097 & .8281 & -1.03 & -4.9 \\
\hline 31 & $L 1=10, L 2=8$ & 5 & .9759 & .9920 & .9654 & .9596 & 1.07 & -.8 \\
\hline 32 & $L 1=10, L 2=8$ & 10 & .9581 & .9916 & .9461 & .9525 & 1.25 & 3.9 \\
\hline 33 & $L 1=10, L 2=8$ & 15 & .9581 & .9916 & .9461 & .9525 & 6.25 & 3.9 \\
\hline
\end{tabular}

\section{CONCLUSIONS}

This paper presented an analytical study about the dynamic power compensation capability of STATCOM for the integration of wind power in a weak distribution network. The study reveals that integrationof wind farm in a weak distribution network is possible due to reactive power compensation by STATCOM. STATCOM prevents large deviations of bus voltage due to reactive power drawn by wind turbine generators. Simulations carried out confirm that STATCOM could provide the fast acting voltage support necessary to prevent the possibility of voltage reduction A Neural Network is also developed in this paper which after training can forecast voltage values on bus 1 and bus 2 of the transmission line on any values of the resistive load connected to transmission line at any time duration. The developed Artificial Neural Network can further be used for further research.

\section{REFERENCES}

[1] Nang Sabai, and Thida Win (2008) "Voltage control and dynamic performance of power transmission system using SVC" World Academy of Science, Engineering and Technology 42 Pp. 425-429

[2] P.Kundur, "Power system stability and control", Mc Graw-Hill, 1994

[3] D Murali ,"Comparison of FACTS devices for power system stability enhancement" International Journal of Computer Applications (0975 - 8887) Volume 8- No.4, Pp. 30-35

[4] H. Yazdanpanahi ,"Application of FACTS devices in transmission expansion to overcome the problems related to delays".

[5] A.E. Hammad, "Analysis of power system stability enhancement by static var compensator", IEEE PWRS, vol 1, no 4, pp. 222-227.

[6]Christian Rehtanz April (2009), ,'New types of FACTS devices for power system security and efficiency" $\mathrm{Pp}-1$ 6.

[7] Hadi Saadat, "Power system analysis", Mc Graw-Hill companies. Inc, 1999.

[8] Edris Abdel, "Series Compensation SchemesReducing the Potential of Sub synchronous Resonance, "IEEE Trans. On power systems, vol. 5 No. 1. Feb1990. Pp. 219-226

[9] Atef Aly El-Emary, "Effect of static VAR compensator upon synchronizing Torque coefficient." Electric Machines and Power Systems 25:371-386, 1977.

[10] A.R. Messina, O. Begovich M. "Analytical investigation of the use of static Var compensators to aid damping of inter area oscillations." Electric Power System Research 21(1999) 199-210.

[11] A.H.M.A. Rahim, M.F. Kandlawala, "Robust STATCOM voltage controller design using loopshaping technique.” Electric Power System Research, vol. 60, Jan. 2004, 61-74.

[12] A.H.M.A., S.A. Al-Baiyat and H.M.Al-Maghrabi, "Robust damping controller design for static compensator," IEE Proceedings Generation Transmission Distribution 149, 4(2002), pp. 491-496.

[13] Wenxin Liu, Ganesh K., Venayagamoorthy and Donald C. Wunsch, II, "Design of an adaptive neural network based power system stabilizer", Trans. Neural Networks, Vol. 16, Issues 5-6, June-July 2003, Pages 891-898.

[14] Srinivas Pillutla and Ali Keyhani, "Power system stabilization based on modular neural network architecture", International Journal of Electrical Power \& Energy Systems, Vol. 19, Issue 6, August 1997, pp. 411-418.

[15] José A.L. Barreiros, André M.D. Ferreira, Carlos Tavares-da-Costa, Jr., Walter Barra, Jr. and João A.P. 
Lopes, "A neural power system stabilizer trained using local linear controllers in a gain-scheduling scheme", International Journal of Electrical Power \& Energy Systems, Volume 27, Issue 7, September 2005, pp. 473479.

[16] Srinivas Pillutla and Ali Keyhani, "Power system stabilization based on modular neural network architecture", International Journal of Electrical Power \& Energy Systems, Vol. 19, Issue 6, August 1997, pp. 411-418.

[17] Shu-Rong Li; Hai-Tao Shi, "Neural network based on excitation controller design of power systems via backstepping", Proc. 2003 International Conference on Machine Learning and Cybernetics, Vol. 2, Issue 6, 2-5 Nov. 2003, pp. 934 - 939.
[18] Ruzic, S.; Vuckovic, A.; Nikolic, N, "Weather sensitive method for short term load forecasting in Electric Power Utility of Serbia”, IEEE Transactions on Power Systems, Vol. 18, Issue: 4, pp. 1581- 1586, Nov. 2003.

[19] Loi Lei Lai, "Intelligent System Applications in Power Engineering: Evolutionary Programming and Neural Networks", John Wiley, NewYork.

[20] W.S. Mc Culloch and W. Pitts. A Logical Calculus of the Ideas Imminent in Nervous Activity. Bulletin of Mathematical Biophysics 5, 115-133, 1943.

[21] D.O. Hebb, The Organization of Behaviour, John Wiley \& Sons. New York (1949). 